\title{
Efficacy of Copper Oxide and Magnesium Oxide Nanoparticles on Controlling Black Scurf Disease on Potato
}

\author{
Ismail, A.M*
}

Received: 5 December 2021 / Accepted: 29 December 2021 / Published online: 30 December 2021. (C) Egyptian Phytopathological Society 2021

\begin{abstract}
Black scurf disease caused by Rhizoctonia solani is common on potato crop worldwide. The current study aimed to evaluate the antifungal activity of CuONPs and MgONPs on $R$. solani in laboratory, greenhouse and field trials. Field trials were conducted under naturally infected fields located in two Governorates, Behera and Menoufia. Potato tubers cv. Spunta were soaked in different concentrations (75, 150 and $200 \mathrm{mg} / \mathrm{L})$ of the tested NPs for 2 hours pre-planting. Disease severity (DS) and disease incidence (DI) of black scurf symptoms on the harvested potato tubers were estimated. Ultrastructural changes in $R$. solani hyphae in response to the tested NPs were also detected using Transmission Electron Microscope (TEM). Physiological and biochemical activities were also determined in potato leaves after 20, 40 and 60 days of planting. In vitro results showed that MgONPs at $200 \mathrm{mg} / \mathrm{L}$ exhibited the greatest inhibitory effect on the mycelial growth of $R$. solani, with inhibition reached $73.47 \%$. Ultrastructural micrographs of TEM images of $R$. solani hyphae confirmed the damage induced by NPs. Greenhouse results exhibited that the great reduction in DI and DS\% was achieved by MgONPs at concentration $200 \mathrm{mg} / \mathrm{L}$, with efficacy reached 85.07 and $93.47 \%$, respectively. The same trend of greenhouse results was observed, of which $\mathrm{MgONPs}$ at concentration $200 \mathrm{mg} / \mathrm{L}$, had significant $(\mathrm{p}<0.05)$ effect in reducing both DI and DS\% in both Menoufia and Behera field trials. Also, MgONPs had a significant $(p<0.05)$ effect in increasing the yield of potato tubers in both field trials. NPs had great impact in increasing enzyme activities, phenols and chlorophyll content when compared to untreated control plants. Energy Dispersive X-ray Spectrometry (EDX) analysis confirmed the presence of CuONPs in the tissues of treated harvested potato tubers compared with the control. The accumulation of CuONPs in edible plant tissues is a critical issue that could impact human health, and this should be taken in consideration when establishing control program for black scurf disease.
\end{abstract}

Key words: Potato, Black scurf, Rhizoctonia solani, chlorophyll, enzymes, nanoparticles, phenols.

*Correspondence: Ismail, A.M.

ma.ah.ismail@gmail.com

\section{Ahmed M. Ismail}

(D) https://orcid.org/0000-0001-9679-640X

Plant Pathology Research Institute, Agricultural

Research Center, 12619, Giza, Egypt.

\section{INTRODUCTION}

Potato (Solanum tuberosum L.) is subjected to numerous fungal diseases such as powdery scab, powdery mildew, early blight, late blight, dry rot, wilt, silver scurf, stem canker and black scurf. Black scurf disease is caused by Rhizoctonia solani (Telomorph: Thanatephorus cucumeris (Frank) Donk). Damage caused by $R$. solani is common in potato crops worldwide, resulting in poor quality of tubers and reduction of yield (Jeger et al., 1996 and Kankam et al., 2021). The disease is very difficult to control due to persistent, long living sclerotial structures of $R$. solani in soil (Zachow et al., 2011). Thus, it is difficult to be entirely controlled, but severity may be limited by following a combination of crop protection strategies for successful disease management (Banyal, 2002).
Crop rotation with non-susceptible crops for $R$. solani for 3-5 years is helpful to reduce both the incidence and severity of this disease. However, rotation is difficult to conduct in the main planting area of potato (Bakali and Martín, 2006). Therefore, alternative methods are needed for controlling this disease.

Nanotechnology is a new emerging and interesting field of sciences which currently applied in many areas. Nanoparticles (NPs) are commonly accepted as materials with two dimensions between 1-100 nm (Ball, 2002). Nanoparticles have potential prospects of use in plant disease management in different ways, such as application in soil, on seeds or foliage (Khandaker et al., 2012). Due to their unique smaller size, larger surface area and better stability, NPs can serve as a preferable chemical (pesticide) delivery system and may also enhance crop yield by nutrient and water management (Rai et al., 2018), suggesting that nanotechnology is being a promising application approach for sustainable agriculture. An array of publications has been demonstrated the antifungal toxicity of CuONPs towards Phytophthora infestans (Giannousi et al., 2013) 
and phytopathogenic fungi, such as $A$. alternata and Botrytis cinerea (Ouda, 2014), A. alternata, Fusariun oxysporum, Curuvularia lunata and Phoma distructiva (Kanhed et al., 2014), tomato Fusarium wilt and Verticillium wilt (Elmer and White, 2016), R. solani (ElShewy et al., 2019) and powdery mildew of rose (Hao et al., 2019), Furthermore, MgONPs have enormous potential as antifungal agent against fungal diseases caused by $R$. solani (El-Argawy et al., 2017), A. alternata, $F$. oxysporum, Rhizopus stolonifer, and Mucor plumbeus (Wani and Shah, 2012), F. oxysporum f. sp. lycopersici (Parizi et al., 2014) and P. nicotianae and Thielaviopsis basicola (Chen et al., 2020).

The aims of the present study were to; (1) investigate the antifungal activity of CuONPs and MgONPs against $R$. solani in in vitro and in vivo trials; (2) detect the ultrastructural changes in $R$. solani hyphae in response to the tested NPs; and (3) determine of physiological and biochemical activities such as peroxidase and polyphenoloxidase enzymes, chlorophyll and phenol contents.

\section{MATERIALS AND METHODS}

\section{Source of NPs and Potato Tubers:}

CuONPs and MgONPs were obtained from Nanotechnology \& Advanced Nano-Materials Laboratory (NANML), Plant Pathology Research Institute (PPRI), Agricultural Research Center (ARC), Giza, Egypt. The morphology and size of such NPs were confirmed using High Resolution Transmission Electron Microscope HR-TEM, with an accelerating voltage of 200 $\mathrm{kV}$ at National Research Centre (NRC), Dokki Giza, Egypt. Apparently healthy tubers cv. Spunta were obtained from Brown Rot Potato Project (ARC), Giza, Egypt.

\section{Source of $R$. solani:}

The isolate of $R$. solani used in this study was provided from Department of Vegetable Diseases Research, (PPRI), (ARC), Giza, Egypt. It was originally isolated from diseased potato tubers with typical black scurf symptoms. The identity of $R$. solani was confirmed by amplification and sequencing of Internal Transcribed Spacer (ITS) region containing; ITS1 and ITS2 regions and the 5.8S rRNA gene using ITS1 and ITS4 primers (White et al., 1990). Genomic DNA extraction was performed using Genomic DNA Mini kit (Geneaid) according to manufacturer's protocol. PCR amplification was done in a reaction containing $1 \mu \mathrm{l}$ of the fungal DNA extract, $2 \mathrm{mM} \mathrm{MgCl}$, 2.5 of 10x PCR buffer, $1.5 \mu \mathrm{L}$ of $10 \mu \mathrm{M}$ of each primer, $2.5 \mu \mathrm{l}$ of $10 \mathrm{mM}$ dNTPs, $0.3 \mu \mathrm{l}$ of $5 \mathrm{U}$
Taq DNA Polymerase and the reaction was completed to $25 \mu \mathrm{L}$ with Nuclease-free water. PCR was conducted in 2720 Thermal Cycler (Applied Biosystem), with initial denaturation at $95^{\circ} \mathrm{C}$ for $2 \mathrm{~min}$, followed by 35 cycles of $95^{\circ} \mathrm{C}$ for $30 \mathrm{sec}, 52^{\circ} \mathrm{C}$ for $30 \mathrm{sec}$, and $72^{\circ} \mathrm{C}$ for $30 \mathrm{sec}$, and the final cycle is a polymerization cycle performed at $72^{\circ} \mathrm{C}$ for $10 \mathrm{~min}$. PCR products were sequenced through a commercial company (Macrogen Inc, South Korea). BLAST analysis was applied for sequences homology at NCBI (http://ncbi.nlm.nih. gov/BLAST).

Effect of NPs on the Mycelial Growth of $\boldsymbol{R}$. solani:

Effect of CuONPs and MgONPs on the mycelial growth of $R$. solani was carried out on potato dextrose agar (PDA) medium using the poisoned media technique (Grover and Moore 1962). PDA medium was supplemented with a series of concentrations $(75,150$ and $200 \mathrm{mg} / \mathrm{L})$ of each NPs. Before solidification, PDA medium was poured into 4 petri plates for each treatment. Plates were then inoculated in the center with $5 \mathrm{~mm}$ fresh mycelial discs of 5 days old culture of $R$. solani and incubated at $24 \pm 2^{\circ} \mathrm{C}$. Negative control plates contained only mycelial discs of $R$. solani. The diameter of the mycelium was measured, and inhibition ratio was calculated for each treatment.

\section{Examination of $R$. solani Using TEM:}

Ultrastructural and morphological changes in the hyphae of $R$. solani treated with CuONPs and $\mathrm{MgONPs}$ at concentration $200 \mathrm{mg} / \mathrm{L}$ were examined using Transmission Electron Microscope (TEM). The fungal hyphae were prepared following the procedure of Chen et al. (2020). Stained specimens were imaged using JEOL-JEM 1010 TEM at acceleration voltage $80 \mathrm{kV}$ at The Regional Centre for Mycology and Biotechnology at Al-Azhar University, Cairo, Egypt.

\section{Greenhouse Trial: \\ Inoculum Preparation:}

The inoculum of the tested $R$. solani was prepared in sterilized glass flasks $(500 \mathrm{ml})$. Each flask contained a mixture of sorghum grains and sand $(2: 1 \mathrm{v} / \mathrm{v})$, the ingredients were mixed well and wetted with tap water and then autoclaved for $30 \mathrm{~min}$ at $121^{\circ} \mathrm{C}$. The flasks were inoculated with $6 \mathrm{~mm}$ mycelial disc of 5 days old culture of $R$. solani. The inoculated flasks were then incubated at $24 \pm 2^{\circ} \mathrm{C}$ for 15 days (Abd El-Aziz et al., 2013).

\section{Preparation of Soil and Pots:}

Soil mixture of peat moss and sand $(2: 1 \mathrm{w} / \mathrm{w})$ was prepared and sterilized with 5\% diluted solution of commercial formalin. Plastic pots 30 
$\mathrm{cm}$ in diameter were sterilized by dipping in 5\% formalin solution for $15 \mathrm{~min}$, then air dried for $24 \mathrm{hr}$. The pots were then filled in with $3 \mathrm{~kg}$ of the previously prepared sterilized soil mixture.

Treatment of Potato Tubers and Inoculation:

The tested NPs were applied by soaking apparently healthy potato tubers in a series of concentrations $(75,150$ and $200 \mathrm{mg} / \mathrm{L})$ of each for $2 \mathrm{hr}$. Each plastic pot was inoculated with $R$. solani inoculum at the rate of $2 \%$ and watered for 5 days before planting (Abd El-Aziz et al., 2013). Potato tubers used for control were soaked in only water for $2 \mathrm{hr}$. Control pots were inoculated with the autoclaved sorghum-sand mixture without $R$. solani. Every two pots represented one replicate and three replicates were used for each treatment. The pots were kept under greenhouse conditions. Treated potato tubers were planted in the plastic pots (one tuber/pot) and they were watered and fertilized when needed.

\section{Field Trials:}

Field trials were conducted in January 2021. Two experiments were established in two different locations i.e., Kom-Hamada, ElBeheira Governorate, and El Khattatba, Menoufia Governorate. Each field of study has been cultivated with potato for several years and had a history of infestation with black scurf pathogen. Potato tubers were soaked for $2 \mathrm{hr}$. in a serious of concentrations $(75,150$ and 200 $\mathrm{mg} / \mathrm{L}$ ) of each tested NPs. Potato tubers used for control were soaked in only tap water for $2 \mathrm{hr}$. Then, the treated tubers were planted in the field plots. Each plot comprised of 3 ridges, ( 3 meters long each), for each concentration, and each ridge represented one replicate. Both trials lasted 90 days then the tubers were harvested and kept in a dry place at room temperature for 2 days for dryness. After that, the harvested tubers were washed carefully to remove soil particles to show up the developed sclerotia of $R$. solani.

\section{Disease Assessment:}

In greenhouse trial, Disease severity (DS) and Disease incidence (DI) were measured on randomly collected 7 tubers for each replicate. In field trials, DS and DI were determined on randomly collected 25 tubers for each replicate. The DS was calculated using the scale of Rauf $e t$ al. (2007):

\footnotetext{
$\mathbf{0}=$ no sclerotia present

$\mathbf{1}=$ less than $1 \%$ of tuber area affected

$\mathbf{2}=1-10 \%$ of tuber area affected

$\mathbf{3}=11-20 \%$ of tuber area affected

$4=21-50 \%$ of tuber area affected

$\mathbf{5}=51 \%$ or more of tuber area affected
}

\author{
Disease Severity (DS) \% = \\ $\sum$ (No. of infected tubers $\times$ No. of scale) \\ Total No. of tubers $X$ highest No. of scale \\ $\times 100$
}

The disease incidence and efficacy were calculated as following:

Disease Incidence (DI) \% =

No. of infected tubers

Total No. of tubers $\times 100$

Efficacy\% = Control - Treatment/Control $\times 100$

\section{Assessment of Yield Parameters:}

The yield parameters i.e., tubers number/plant, potato tubers fresh weight $(\mathrm{kg}) /$ plant and dry weigh $(\mathrm{g})$ were determined. Dry weight $(\mathrm{g})$ was estimated in $100(\mathrm{~g})$ fresh weight of potato tubers following the method of Zelalem et al. (2009).

Assessment of Enzymatic Activity:

The activity of Polyphenoloxidase (PPO) enzyme was estimated in potato leaves after 20, 40 and 60 days of planting according to Matta and Dimond (1963). Polyphenoloxidase was expressed as change in absorbance at $495 \mathrm{~nm}$. The activity of peroxidase (PO) was estimated as mentioned by Allam and Hollis (1972). Peroxidase was expressed as change in the absorbance at $422 \mathrm{~nm}$ every $10 \mathrm{sec}$ for 1 minute period.

\section{Determination of Phenols and Chlorophyll \\ Contents:}

Phenol content was colorimetrically estimated in potato leaves after 20,40 and 60 days of planting date using the "Folin and Ciocaltei" reagent as described by Snell and Snell (1953). Chlorophyll A and B were estimated in potato leaves after 20, 40 and 60 days of planting according to $\mathrm{Su}$ et al. (2010). Chloroplast pigments were determined by measuring the optical density at 663 and $645 \mathrm{~nm}$ and calculated using the formula described by Arnon (1949). Measurements were done using Unico-2000 UV spectrophotometer (Unico Scientific, Hong Kong, China) at (NANML), Plant Pathology Research Institute (PPRI), Agricultural Research Center (ARC), Giza, Egypt.

\section{Detection of NPs in Potato Tubers:}

The presence and accumulation of CuONPs and MgONPs in the tissues of harvested potato tubers was determined using Energy Dispersive X-ray Spectrometry (EDX) microanalysis (Scimeca et al., 2018) at National Research Centre (NRC), Giza, Egypt. Dry ashing of potato tuber tissues was done before EDX analysis following the method of Gichuhi et al. (2014). 


\section{Statistical analysis:}

The obtained data were subjected to statistical analysis of variance according to Snedecor and Cochran (1980) and treatments means were separated by Fisher's protected least significant difference (LSD). Data were analyzed by software SPSS $8 \cdot 0$.

\section{RESULTS}

\section{Identification of Potato Black Scurf} Pathogen:

PCR amplification of the ITS1, 5.8S rRNA and ITS2 region resulted in a product of approximately $650 \mathrm{bp}$. BLAST search of the sequenced DNA product against a variety of nucleotide sequence in GenBank databases revealed $100 \%$ similarity with $R$. solani strain

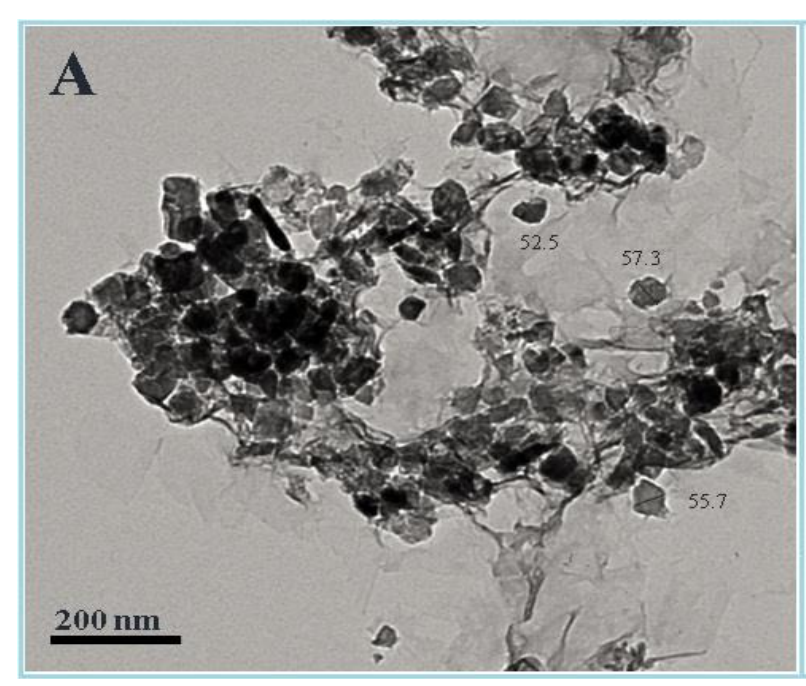

Figure (1): TEM micrograph images of MgONPs (A)

Effect of NPs on the mycelial growth of $R$. solani:

Results in Table (1) illustrate the antifungal effect of CuONPs and MgONPs on the mycelial growth of $R$. solani in vitro. All tested concentrations of the tested NPs reduced the mycelial growth of $R$. solani relative to control treatment. The treatment with MgONPs at 200 $\mathrm{mg} / \mathrm{L}$ exhibited the greatest inhibitory effect in reducing the growth of $R$. solani, with inhibition

Table (1): Effect of CuONPs and MgONPs on the mycelial growth of $R$. solani in vitro

\begin{tabular}{lccc}
\hline \multicolumn{1}{c}{ Treatment } & Concentration $(\mathrm{mg} / \mathrm{L})$ & Mycelial growth $(\mathrm{mm})$ & Inhibition $\%$ \\
\hline \multirow{3}{*}{ CuONPs } & 75 & 60.03 & 33.30 \\
& 150 & 50.42 & 43.98 \\
& 200 & 34.18 & 62.02 \\
\hline \multirow{2}{*}{ MgONPs } & 75 & 44.93 & 50.08 \\
& 150 & 36.14 & 59.84 \\
\hline Control & 200 & 23.88 & 73.47 \\
\hline LSD at 0.05 & 0 & 90.00 & - \\
\hline
\end{tabular}

CBS 280.36 (AG-3) (GenBank accession no. MH855798). The obtained sequence was deposited in GenBank database under accession no: OK275407. Sequence analysis of the ITS region confirmed that the $R$. solani isolate belongs to the AG-3 group.

\section{Characterization of NPs Using TEM:}

A close look at HR-TEM images at $200 \mathrm{~nm}$ confirmed the nanometer form with size ranges from 52.5 to $57.3 \mathrm{~nm}$ for MgONPs (Fig. 1A), and 23.1 to $27.3 \mathrm{~nm}$ for CuONPs (Fig. 1B). MgONPs were generally monodispersed, sometimes irregular and mostly have cubic-like shape (Fig. 1A). The nanoparticles of CuONPs were spherical and tended to agglomerate by forming aggregations, indicating unsatisfactory dispersibility (Fig.1B).

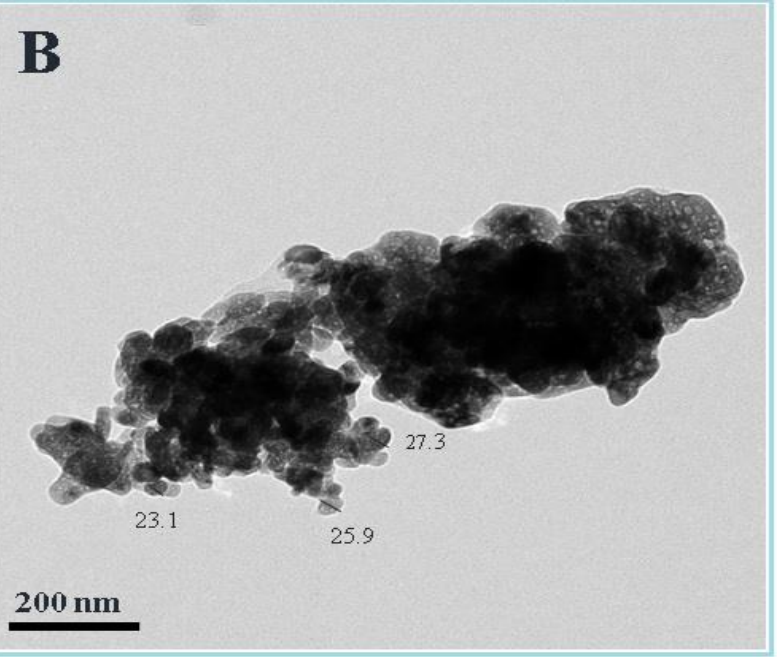

reached $73.47 \%$ followed by CuONPs at 200 $\mathrm{mg} / \mathrm{L}$, which recorded $62.02 \%$ inhibition of the growth of $R$. solani. On the other hand, the low concentrations of CuONPs had weak effect on the growth of $R$. solani. Moreover, the inhibitory effect of CuONPs and MgONPs was decreased gradually with decreasing concentration. None of the tested NPs resulted in a complete inhibition of $R$. solani growth in vitro. 
Examination of $\boldsymbol{R}$. solani Using TEM:

Cross and longitudinal sections of $R$. solani mycelia were imaged through TEM (Fig. 2). Treatment with CuONPs revealed a malformation of fungal cell nucleus, degradation or deterioration of the fungal cell wall and coagulation of cytoplasm and most of cell organelles (Fig.2B, C) when compared with control treatment (Fig.2A). While treatment of $\mathrm{MgONPs}$ caused loss of matrix in vacuoles and obvious vacuolization, plasmolysis, cell wall thickening, conglomeration of cytoplasm and nucleus malformation relative to control treatment (Fig.2D, E).

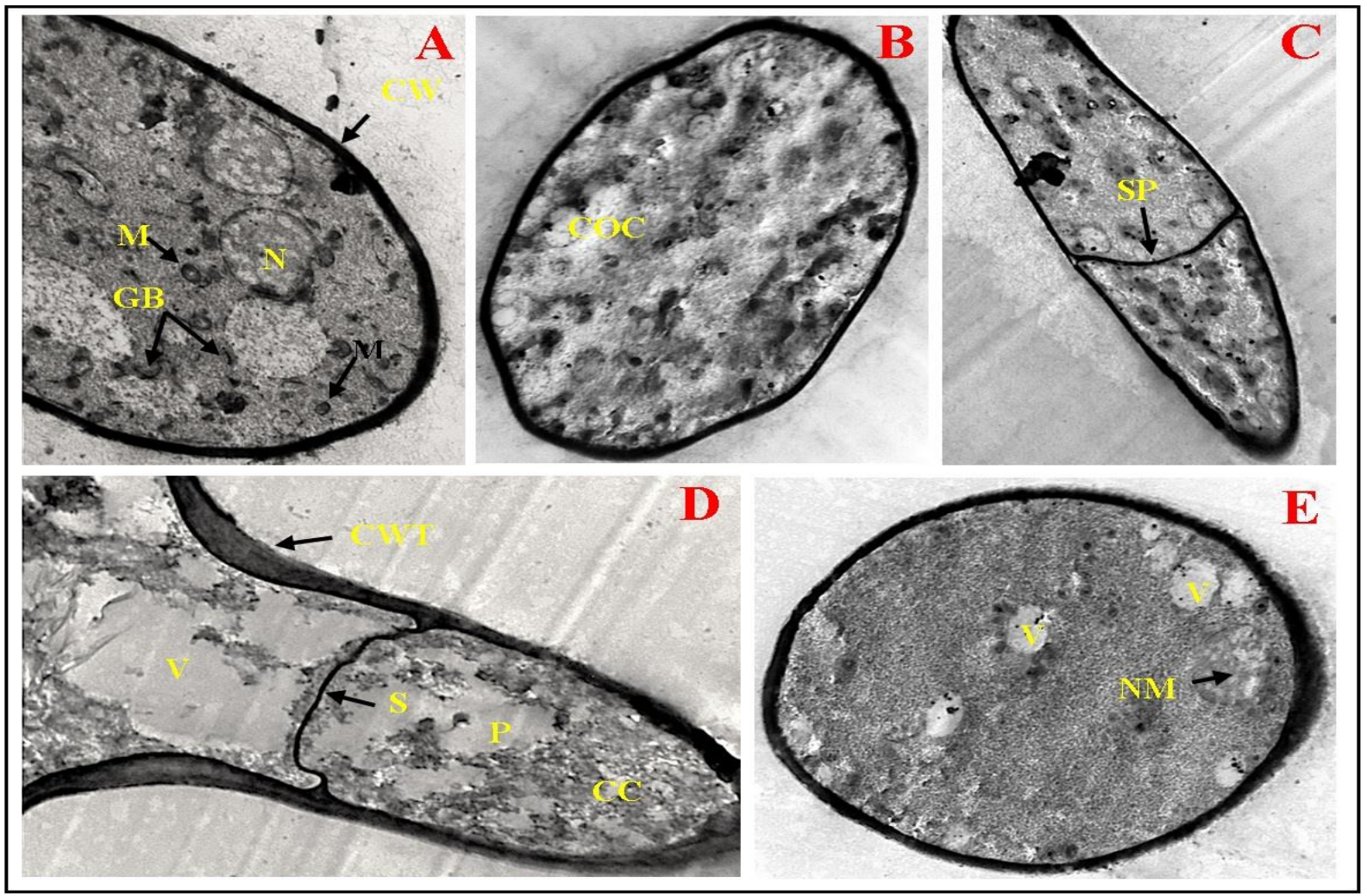

Figure (2): TEM of $R$. solani hyphae (A) transverse section of untreated hypha (control), mitochondria (M); cell wall (CW); Nucleus (N) and Golgi bodies (GB)). (B) transverse and (C) longitudinal sections of treated hyphae with $\mathrm{CuONPs}$ at $200 \mathrm{mg} / \mathrm{L}$, showing cell organs coagulation (COC) and disappearance of septal pore (SP); (D) transverse and (E) longitudinal sections of treated hyphae with MgONPs at $200 \mathrm{mg} / \mathrm{L}$, showing that cell walls become thick (CWT), loss of matrix in vacuoles and obvious vacuolization $(\mathrm{V})$, plasmolysis (P), conglomeration of cytoplasm (CC) and nucleus malformation (NM).

\section{Greenhouse Trial:}

Data in Table (2) indicate that the tested CuONPs and MgONPs at all concentrations reduced DI and DS\% of black scurf disease under greenhouse conditions over control. The greatest effect was obtained by MgONPs at 200 $\mathrm{mg} / \mathrm{L}$ and $150 \mathrm{mg} / \mathrm{L}$, which revealed a noticeable reduction in DI and DS\%. Also, CuONPs revealed a significant reduction in DI\% and DS\% at $200 \mathrm{mg} / \mathrm{L}$. It was clear that increasing the concentration of both the tested NPs from 75 to $200 \mathrm{mg} / \mathrm{L}$ increased gradually their effects in reducing DI\% and DS\% of black scurf disease on potato tubers.

\section{Field Trials:}

The evaluated CuONPs and MgONPs exhibited significant decrease in DI and DS of black scurf symptoms under field conditions of Behera and Menoufia trials (Tables 3, 4). In Behera trial, concentration $200 \mathrm{mg} / \mathrm{L}$, MgONPs recorded significant decrease in DI of black scurf with efficacy reaching $76.67 \%$ and DS with efficacy reaching $76.02 \%$ (Table .3). However, CuONPs at the same concentration showed lower efficacy than MgONPs in such respect, but still significantly effective than the lower concentrations and control. In Menoufia trial, the same trend was obtained, of which the higher concentration $(200 \mathrm{mg} / \mathrm{L})$ of each of CuONPs and MgONPs had the greatest effect in decreasing DI and DS of black scurf symptoms (Table .4). Additionally, treatment of MgONPs at $150 \mathrm{mg} / \mathrm{L}$ resulted also in a remarkable decrease in DI and DS\% of black scurf 
symptoms when compared with the lower concentration and control in both trials. No phytotoxic effect was observed on potato leaves

Table (2): Evaluation of CuONPs and MgONPs against black scurf disease under greenhouse conditions

\begin{tabular}{lccccc}
\hline Treatment & $\begin{array}{c}\text { Concentration } \\
(\mathrm{mg} / \mathrm{L})\end{array}$ & DI $\%$ & Efficacy $\%$ & DS \% & Efficacy \% \\
\hline \multirow{3}{*}{ CuONPs } & 75 & 76.18 & 20.01 & 17.87 & 44.98 \\
& 150 & 57.14 & 40.00 & 11.65 & 64.13 \\
\hline \multirow{2}{*}{ MgONPs } & 200 & 28.57 & 70.00 & 4.32 & 86.69 \\
& 75 & 61.90 & 35.00 & 10.29 & 68.31 \\
\hline Control & 150 & 19.10 & 79.94 & 3.14 & 90.33 \\
\hline LSD at 0.05 & 200 & 14.22 & 85.07 & 2.12 & 93.47 \\
\hline
\end{tabular}

Table (3): Evaluation of CuONPs and MgONPs against black scurf disease under field conditions in Behera Governorate

\begin{tabular}{lccccc}
\hline \multirow{2}{*}{ Treatment } & $\begin{array}{c}\text { Concentration } \\
(\mathrm{mg} / \mathrm{L})\end{array}$ & DI \% & Efficacy \% & DS \% & Efficacy \% \\
\cline { 3 - 6 } & 75 & 30.67 & 23.32 & 18.55 & 23.59 \\
& 150 & 24.00 & 40.00 & 14.82 & 38.96 \\
CuONPs & 200 & 13.33 & 66.67 & 7.02 & 71.08 \\
& 75 & 26.67 & 33.32 & 15.75 & 35.13 \\
& 150 & 22.67 & 43.32 & 9.98 & 58.89 \\
\multirow{3}{*}{ MgONPs } & 200 & 9.33 & 76.67 & 5.82 & 76.02 \\
& 0 & 40.00 & - & 24.28 & - \\
\hline Control & & 5.69 & & 1.89 & - \\
\hline LSD at 0.05 & & &
\end{tabular}

Table (4): Evaluation of CuONPs and MgONPs against black scurf disease under field conditions in Menoufia Governorate

\begin{tabular}{lccccc}
\hline \multirow{2}{*}{ Treatment } & $\begin{array}{c}\text { Concentration } \\
(\mathrm{mg} / \mathrm{L})\end{array}$ & DI \% & Efficacy \% & DS \% & Efficacy \% \\
\cline { 3 - 6 } & 75 & 25.33 & 29.63 & 11.99 & 27.81 \\
\hline \multirow{3}{*}{ CuONPs } & 150 & 21.33 & 40.75 & 11.12 & 33.05 \\
& 200 & 10.67 & 70.36 & 5.65 & 65.98 \\
\hline \multirow{3}{*}{ MgONPs } & 75 & 25.33 & 29.63 & 10.41 & 37.32 \\
& 150 & 20.00 & 44.44 & 6.98 & 57.97 \\
\hline Control & 200 & 8.00 & 77.77 & 4.59 & 72.36 \\
\hline LSD at 0.05 & 0 & 36.00 & - & 16.61 & - \\
\hline
\end{tabular}

Effect of CuONPs and MgONPs on the Yield of Potato Plants:

Data presented in Tables $(5,6)$ show yield parameters of potato plants under field conditions. The tested NPs had significant effect in increasing yield of potato tubers when compared with control. Potato plants treated with $\mathrm{MgONPs}$ at concentration $200 \mathrm{mg} / \mathrm{L}$ in Behera trial showed significant increase in tuber number/plant with value reached 12.60 as well as fresh $(2.67 \mathrm{~kg})$ and dry weight $(22.11 \mathrm{~g})$. At the same concentration, treatment of CuONPs exhibited also significant increase in tubers number/plant (10.73), fresh weight $(2.64 \mathrm{~kg})$ and dry weight $(18.80 \mathrm{~g})$ relative to control (Table .5). The same trend of the results was also observed in Menoufia trial, of which the highest concentration of MgONPs exhibited the highest values of tubers number/plant (11.13), fresh weight $(2.92 \mathrm{~kg})$ and dry weight $(21.35 \mathrm{~g})$ followed by CuONPs at the same concentration (Table .6).

Assessment of Enzymatic Activities, Total Phenols and Chlorophyll:

The activities of PO and PPO, total phenols and chlorophyll contents were estimated three times with 20-days interval after planting (Tables .7, 8). Based on the obtained results, the 
highest activity of PO and PPO was recorded in leaves of potato plants treated with MgONPs at concentration $200 \mathrm{mg} / \mathrm{L}$ after 20 days of planting with values reaching 1.108 and 0.306 OD/ $10 \mathrm{sec} / \mathrm{g} \mathrm{FW}$, respectively (Table .7). The activity of PO and PPO was gradually decreased by time to reach $0.992 \Delta \mathrm{A} 422 / 10 \mathrm{sec} / \mathrm{g} \mathrm{FW}$ for $\mathrm{PO}$ and $0.272 \Delta \mathrm{A} 495 / 10 \mathrm{sec} / \mathrm{g}$ FW for PPO after 60 days of planting. On the other hand, potato plants treated with CuONPs at concentration $200 \mathrm{mg} / \mathrm{L}$ exhibited also great activity of $\mathrm{PO}$ and PPO after 20 days of planting with values reached $0.791 \Delta \mathrm{A} 422 / 10 \mathrm{sec} / \mathrm{g} \mathrm{FW}$ and 0.282 $\triangle \mathrm{A} 495 / 10 \mathrm{sec} / \mathrm{g} \mathrm{FW}$, respectively. This activity was slightly decreased by time.
After 20 days of planting, potato plants treated with high concentrations of CuONPs and MgONPs revealed the highest content of total phenols with values reaching 7.66 and 8.25 $\mathrm{mg} / \mathrm{g}$ FW (Table .8). Conversely, potato plants treated either with CuONPs or MgONPs at all concentrations displayed a gradual increase in chlorophyll contents started after 20 days from planting until the fortieth day (Table .8). After 40 days, phenols content in potato leaves was gradually decreased. The results elucidated in Table (8) show that the lowest concentrations 75 and $150 \mathrm{mg} / \mathrm{L}$ were also effective in increasing phenols and chlorophyll contents in potato plants when compared to control.

Table (5): Effect of CuONPs and MgONPs on the yield of potato plants cv. Spunta cultivated in Behera Governorate

\begin{tabular}{lcccc}
\hline Treatment & $\begin{array}{c}\text { Concentration } \\
(\mathrm{mg} / \mathrm{L})\end{array}$ & $\begin{array}{c}\text { No. of } \\
\text { tubers/Plant }\end{array}$ & $\begin{array}{c}\text { Bresh weight/ } \\
\text { Plant }(\mathrm{kg})\end{array}$ & $\begin{array}{c}\text { Dry weight }(\mathrm{g}) / 100 \mathrm{~g} \text { of } \\
\text { fresh weigh }\end{array}$ \\
\hline \multirow{3}{*}{ CuONPs } & 75 & 9.60 & 1.94 & 16.95 \\
& 150 & 10.06 & 2.29 & 17.40 \\
\hline \multirow{3}{*}{ MgONPs } & 200 & 10.73 & 2.64 & 19.80 \\
& 75 & 10.00 & 2.48 & 19.98 \\
\hline Control & 150 & 12.33 & 2.53 & 22.11 \\
\hline LSD at 0.05 & 200 & 12.60 & 2.67 & 1.80 \\
\hline
\end{tabular}

Table (6): Effect of CuONPs and MgONPs on the yield of potato plants cv. Spunta cultivated in Menoufia Governorate

\begin{tabular}{lcccc}
\hline \multirow{2}{*}{ Treatment } & \multirow{2}{*}{$\begin{array}{c}\text { Concentration } \\
(\mathrm{mg} / \mathrm{L})\end{array}$} & $\begin{array}{c}\text { No. of } \\
\text { tubers/Plant }\end{array}$ & $\begin{array}{c}\text { Fresh weight/ Plant } \\
(\mathrm{kg})\end{array}$ & $\begin{array}{c}\text { Dry weight }(\mathrm{g}) / 100 \mathrm{~g} \text { of } \\
\text { fresh weigh }\end{array}$ \\
\cline { 3 - 5 } CuONPs & 75 & 8.33 & 2.37 & 16.28 \\
& 150 & 9.00 & 2.46 & 16.37 \\
\hline \multirow{3}{*}{ MgONPs } & 200 & 10.46 & 2.61 & 18.46 \\
\hline Control & 75 & 9.40 & 2.53 & 18.19 \\
\hline LSD at 0.05 & 150 & 9.66 & 2.86 & 21.35 \\
\hline
\end{tabular}

Table (7): Effect of CuONPs and MgONPs on oxidative enzyme activity of PO and PPO in potato plants cv. Spunta

\begin{tabular}{lccccccc}
\hline \multirow{2}{*}{ Treatment } & $\begin{array}{c}\text { Concentration } \\
(\mathrm{mg} / \mathrm{L})\end{array}$ & \multicolumn{2}{c}{$\begin{array}{c}\text { PO } \\
(\Delta \mathrm{A} 422 / 10 \mathrm{sec} / \mathrm{g} F \mathrm{~F})\end{array}$} & \multicolumn{3}{c}{ PPO } \\
& & \multicolumn{2}{c}{ Days after planting } & \multicolumn{3}{c}{ Days after planting } \\
& & 20 & 40 & 60 & 20 & 40 & 60 \\
\hline \multirow{3}{*}{$\mathrm{CuONPs}$} & 75 & 0.541 & 0.511 & 0.487 & 0.176 & 0.166 & 0.158 \\
& 150 & 0.587 & 0.547 & 0.521 & 0.224 & 0.214 & 0.203 \\
& 200 & 0.791 & 0.755 & 0.719 & 0.282 & 0.270 & 0.257 \\
\hline \multirow{3}{*}{$\mathrm{MgONPs}$} & 75 & 0.674 & 0.639 & 0.608 & 0.220 & 0.208 & 0.198 \\
& 150 & 0.930 & 0.883 & 0.841 & 0.259 & 0.247 & 0.235 \\
& 200 & 1.108 & 1.041 & 0.992 & 0.306 & 0.285 & 0.272 \\
\hline Control & 0 & 0.505 & 0.482 & 0.459 & 0.147 & 0.140 & 0.133 \\
\hline
\end{tabular}

$\mathrm{OD}=$ Optical density $; \mathrm{FW}=$ fresh weight $\mathrm{PO}=$ peroxidase $\mathrm{PPO}=$ polyphenoloxidase 
Ismail, A.M.

Table (8): Effect of CuONPs and MgONPs on total phenols and chlorophyll in potato plants cv. Spunta

\begin{tabular}{lccccccc}
\hline \multirow{2}{*}{ Treatment } & $\begin{array}{c}\text { Concentration } \\
(\mathrm{mg} / \mathrm{L})\end{array}$ & \multicolumn{3}{c}{ Total phenols (mg/g FW) } & \multicolumn{3}{c}{ Total chlorophyll (mg/g FW) } \\
& 75 & 20 & 40 & 60 & 20 & 40 & 60 \\
\hline \multirow{3}{*}{ DuONPs } & 75 & 4.67 & 4.26 & 4.03 & 33.40 & 38.14 & 36.67 \\
& 150 & 5.32 & 4.79 & 4.56 & 33.97 & 40.73 & 38.21 \\
& 200 & 7.66 & 7.12 & 6.72 & 35.42 & 46.29 & 42.54 \\
\hline \multirow{3}{*}{ MgONPs } & 75 & 6.58 & 6.08 & 5.94 & 39.22 & 44.23 & 40.21 \\
& 150 & 7.46 & 7.11 & 6.83 & 40.23 & 47.33 & 44.12 \\
\hline Control & 200 & 8.25 & 7.49 & 7.32 & 46.54 & 48.75 & 45.32 \\
\hline
\end{tabular}

\section{Detection of CuONPs and MgONPs in Potato}

Tubers:

Energy dispersive X-ray (EDX) spectrum analysis confirmed the presence of CuONPs and MgONPs in the tissues of harvested potato tubers (Fig. 3A, B) comparing to control (C). Other elements were also determined, and their weight percentages are presented in the incorporated Tables in Figure 3.

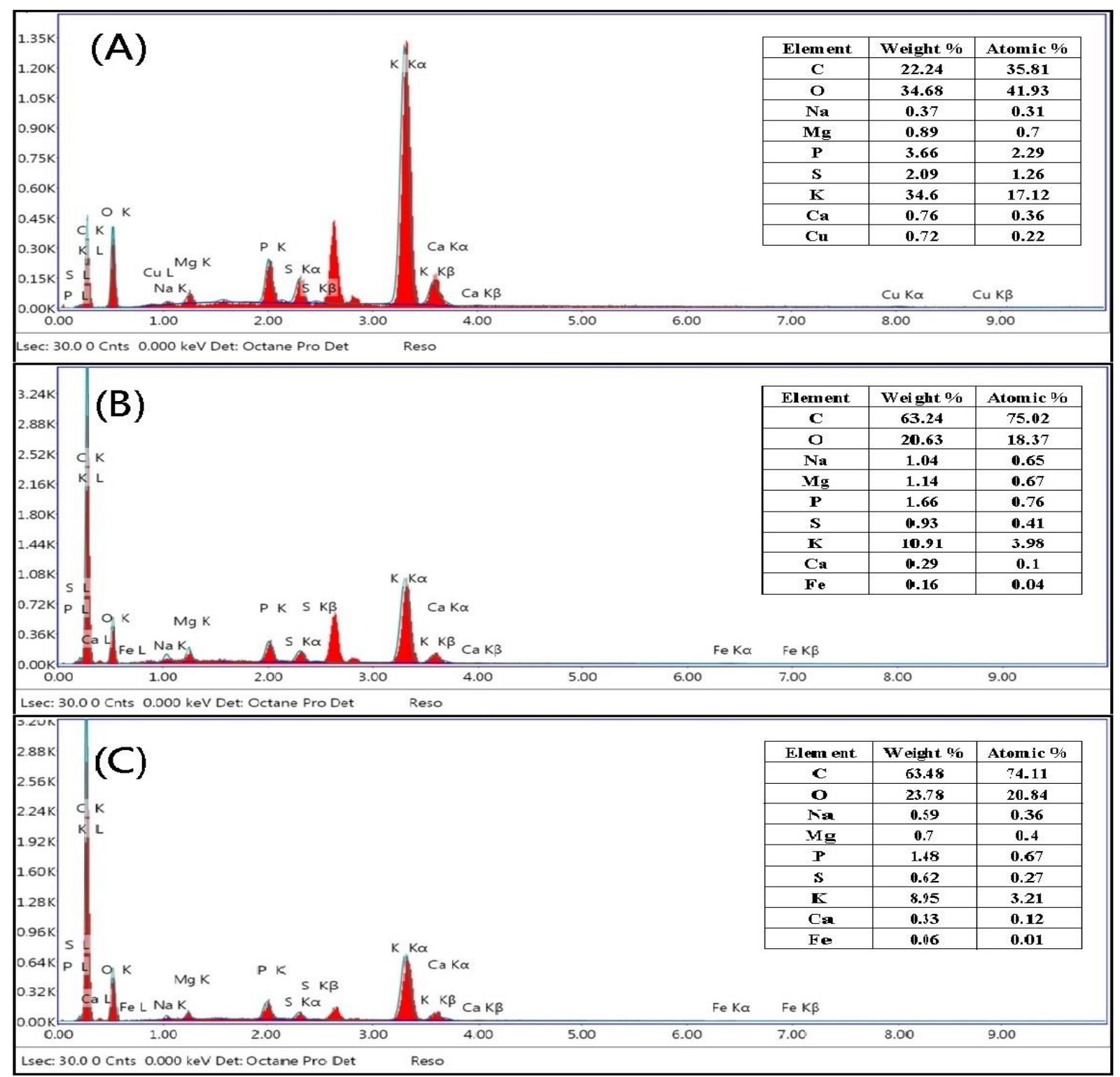

Figure (3): Energy Dispersive X-ray Spectrometry (EDX) profiles of harvested potato tubers treated with CuONPs (A), MgONPs (B) and untreated control (C) showing the weight percentages of NPs and other elements. 


\section{DISCUSSION}

The group of multinucleate $R$. solani Kühn (teleomorph: Thanatephorus cucumeris) is the most extensively studied and widely recognized species. Hyphal anastomosis has been used for AG allocation of Rhizoctonia isolates, however it is not sufficient to delineate them at the subgroup level (Fang et al., 2013). According to Sharon et al. (2008), sequencing the ITS-5.8S rDNA region is considered to be the appropriate method for delineation of multinucleate and binucleate Rhizoctonia isolates into AGs and subgroups. Therefore, the results of amplification and sequencing of ITS-5.8S rDNA region confirmed that the tested isolate of $R$. solani belongs to AG3 group.

In vitro results of the current study elucidated the antifungal capacity of CuONPs and MgONPs at all tested concentrations to inhibit the mycelial growth of $R$. solani, when compared with control. The efficacy was high at concentration $200 \mathrm{mg} / \mathrm{L}$ and decreased with decreasing the concentration. Similar results were given by El-Shewy et al. (2019) who reported that CuONPs inhibited the growth of $R$. solani by $55.19 \%$ at concentration $200 \mu \mathrm{l} / \mathrm{L}$. The recent study of Oussou-Azo et al. (2020) demonstrated that the mycelial growth of Colletotrichum gloeoesporioides was inhibited by $76.8 \%$ with $\mathrm{Cu}-\mathrm{NP}$ at concentrations of 200 $\mathrm{mg} / \mathrm{ml}$. Moreover, Kanhed et al. (2014) reported that CuONPs showed remarkable activity against $A$. alternata, $F$. oxysporum, Curvularia lunata and Phoma distructiva.

Based on the literature search, there are no reports on the use of MgONPs against potato black scurf caused by $R$. solani. However, the recent study of Ahmed et al. (2021) indicated that the CS-Mg nanocomposite had a remarkable antimicrobial activity against $A$. oryzae and $R$. solani on rice. Our results revealed that MgONPs at concentration 200 $\mathrm{mg} / \mathrm{L}$ had the greatest inhibitory effect against $R$. solani with an efficacy reached $73.47 \%$. Similar to our results, El-Argawy et al. (2017) stated that MgONPs at concentration $100 \mathrm{ppm}$ inhibited the mycelial growth of $R$. solani with efficacy value of $67.44 \%$. Previous in vitro studies demonstrated also the inhibitory effect of $\mathrm{MgONPs}$ on the germination of spores of $A$. alternata, $F$. oxysporum, Rhizopus stolonifer and Mucor plumbeus (Wani and Shah, 2012), mycelial growth of $F$. oxysporum f. sp. lycopersici (Parizi et al., 2014), and Phytophthora nicotianae and Thielaviopsis basicola (Chen et al., 2020). Our results revealed that the antifungal activity of CuONPs and MgONPs restrained the mycelial growth of $R$. solani under all tested concentrations, in a dose-dependent manner, which is consistent with other metal nanoparticles (RodriguezGonzalez et al., 2016 and Sun et al., 2018). From these perspectives, our study indicates the benefit of using MgONPs as a nonphytotoxic fungicide to control black scurf disease.

Ultrastructural micrographs TEM images of $R$. solani hyphae confirmed the damage induced by treatment with CuONPs and MgONPs. The treatment with CuONPs revealed that malformation and irregular disposition of cell organelles were clearly visible. The same trend of our results was also reported by El-Shewy et al. (2019). Moreover, Xi et al. (2018) stated that exposure of $R$. solani hyphae to 1,2,4,9tetrahydro-3-thia-9-aza-fluorene caused disappearance of mitochondrial intermembrane space and obvious vacuolization. Our results revealed that exposer of $R$. solani hyphae to MgONPs resulted in cell wall thickening, loss of matrix in vacuoles and obvious vacuolization autolysis, depletion of hyphal cytoplasm and organelles. Likewise, Chen et al. (2020) reported the same effect of MgONPs at concentration $500 \mu \mathrm{g} / \mathrm{ml}$ against hyphae of $T$. basicola and P. nicotianae.

Considering the greenhouse and field experimental results, there are reasons to believe that CuONPs and MgONPs might be very suitable alternatives to fungicides for black scurf disease control. CuONPs displayed satisfied results at concentration $200 \mathrm{mg} / \mathrm{L}$ against $R$. solani in both greenhouse and field trials when compared with control. Almost, the same trend of our results was recorded by El-Shewy et al. (2019) who stated that CuONPs at $200 \mu \mathrm{l} / \mathrm{L}$ caused a $100 \%$ reduction in DI and DS of black scurf in the field trials. Copper-based NPs displayed effectiveness in controlling tomato late blight caused by Phytophthora infestans (Giannousi et al., 2013) as well as several fungal diseases including, A. alternata and Botrytis cinerea (Ouda, 2014), tomato Fusarium wilt, and Verticillium wilt (Elmer and White, 2016), powdery mildew of rose (Hao et al., 2019), and avocado fruit rot (Hassan et al., 2021).

$\mathrm{MgONPs}$ exhibited the superior efficacy in reducing DI and DS under greenhouse and field conditions, being the higher concentration 200 $\mathrm{mg} / \mathrm{L}$ was the greatest. Similarly, throughout greenhouse trial, El-Argawy et al. (2017) demonstrated that MgONPs at $100 \mathrm{ppm}$ was successfully able to reduce pre-emergence, post- 
emergence damping-off and root rot disease severity of sugar beet caused by $R$. solani. Other studies exhibited the antifungal activity of MgONPs against foliar and soilborne phytopathogens. For example, Chen et al. (2020) stated that the application of MgONPs at $500 \mu \mathrm{g} / \mathrm{mL}$ was highly effective against black shank and black root rot pathogens $P$. nicotianae and Thielaviopsis basicola. Furthermore, Liao et al. (2019) reported that the application of MgONPs at $200 \mu \mathrm{g} / \mathrm{mL}$ significantly reduced disease severity of bacterial leaf spot on tomato under field conditions. None of the tested nanomaterials exhibited phytotoxicity on potato plants during the experiment progress. However, the phytotoxicity and biocompatibility of NPs toward potato plants need to be investigated in consequent studies.

The comprehensive mechanisms of NPs against phytopathogens in vitro and in vivo are not clarified in this study. These mechanisms could be discussed in the light of the previous studies. The biocidal activity of CuNPs could be attributed to the effect of the CuNPs and/or the copper ions discharged from CuNPs. Because of the great surface area of the NPs, it could be strongly adsorbed onto the surface of the microbial cells resulting in disruption of cell permeability and release of integral components (Raffi et al., 2010). It has been reported that $\mathrm{Cu}$ interacts with microorganisms in different ways including cell membrane permeabilization, membrane lipid peroxidation, protein alteration, and denaturation of nucleic acids, ultimately leading to cell death (Oussou-Azo et al., 2020). The antifungal behavior of MgONPs includes: injuring the cell plasmalemma originating from the direct physical interaction and affecting energy metabolism and cell membrane potential (Cai et al., 2018a), vacuolation and disorganized enterocytes (Chen et al., 2020). In addition, Mg is an important element of structural tissues, such as lignin, suberin, and the middle lamella, together with $\mathrm{Ca}$, which makes some pectic substances more resistant to degradation by pectolytic enzymes of various bacterial and fungal pathogens (Huber and Jones, 2013). The different inhibitory mechanisms of MgONPs are discussed in details in the very recent study of Saied et al. (2021).

The results of field trials revealed that under treatments with CuONPs and MgONPs, all concentrations significantly enhanced potato yield compared to control. These results are supported by previous studies, which reported that $\mathrm{Cu}$ plays an important role in plant growth and development, as well as productivity (Xue et al., 2014 and Ngo et al., 2014). Interestingly, Elmer and White (2016) reported that CuONPs was the best among other six metallic oxide nanoparticles $(\mathrm{ZnO}, \mathrm{TiO}, \mathrm{AlO}, \mathrm{FeO}, \mathrm{NiO}$, or $\mathrm{MnO})$ in their efficiency to improve the growth of tomato and eggplants grown in soil infested with Verticillium dahliae and F. oxysporum f.sp. lycopersici, respectively. Conversely, Sarkar et al. (2020) reported that CuONPs at higher concentration $\left(0.05 \mathrm{mg} / \mathrm{mL}^{-1}\right)$ caused a significant reduction of seeds vigor of Lens culinaris compared to control, indicating its toxic effects to the plants. Additionally, Nair and Chung (2014) stated that the higher concentration of CuONPs reduced the shoot growth, weight, and total chlorophyll content in soybean. On the other hand, Chen et al. (2020) demonstrated that there was a significant improvement in wheat root growth and grain yield after foliar MgONPs application under greenhouse conditions. Moreover, Cai et al. (2018b) found that MgONPs enhanced tobacco growth under greenhouse conditions. Additionally, Raliya et al. (2014) demonstrated that biosynthesized MgONPs improved shootroot growth (18.2 to 49.2\%) and chlorophyll photosynthetic pigment $(76.1 \%)$ in clusterbean (Cyamopsis tetragonoloba). Based on the previous published results, it was not surprising that MgONPs and CuONPs displayed a positive effect on the growth of potato indicated by number and biomass of potato tuber in both field trials.

Enzyme activity of PO and PPO was estimated in potato leaves in response to treatments with CuONPs and MgONPs. All tested NPs exhibited a noticeable tendency of an increase in PO and PPO after 20 days of planting, but to a limited extent. The trend of our results was supported by previous studies, which reported that applied copper-based NPs compounds increased the antioxidant systems, including superoxide dismutase and PO activities and total antioxidant levels (Regier et al., 2015 and Singh et al., 2017). A similar kind of results was observed by El-Shewy et al. (2019) where potato plants treated with CuONPs exhibited a noticeable increase in PO and PPO enzymes. Furthermore, Nair and Chung (2014) reported that the CuONPs increased the PPO and lignin contents in soybean plants. This increment was in a concentration-dependent manner, being the higher concentrations induced higher enzyme activity. A similar kind of increase in the defense related enzymes was observed by Sarkar et al. (2020) who demonstrated that catalase, ascorbate 
peroxidase, PPO and superoxide dismutase activities have also steadily increased in tobacco plants by increasing concentration of CuONPs. Contrarywise, Yang et al. (2020) under hydroponic conditions found out that activity of both catalase and superoxide dismutase was decreased in rice leaves treated with CuONPs at the concentration of $250 \mathrm{mg} / \mathrm{L}$. Our results showed that MgONPs displayed a trend similar to that observed for CuONPs treatment, which was concentration dependent. Furthermore, the higher concentration $200 \mathrm{mg} / \mathrm{L}$ of $\mathrm{MgONPs}$ induced higher activity in both PO and PPO enzymes. Likewise, Cai et al. (2018b) found out that the higher concentration $250 \mu \mathrm{g} / \mathrm{mL}$ of MgONPs enhanced the activity of the superoxide dismutase and PO enzymes. While, the low concentrations of 50 and $150 \mu \mathrm{g} / \mathrm{mL}$ revealed lower activity. By contrast, Ramadan et al. (2020) stated that a higher concentration 40 mg L $\mathrm{L}^{-1}$ of MgONPs, exhibited low activity of PO in soybean plants. El-Argawy et al. (2017) reported also that MgONPs had a positive effect on the activity of PPO in sugar beet plants. The increased production of the antioxidant molecule under the influence of NPs confirms the regulation of antioxidant system as a response to NPs interaction with plant (Da Costa and Sharma, 2016).

Chlorophylls have an important role in photosynthesis system, which highly correlate with plant biomass and recover and productivity (Karamanos et al., 2004 and Regier et al., 2015). In this regard, chlorophyll and phenol contents were estimated in potato plants in responses to treatments with CuONPs and MgONPs. Only MgONPs, when compared to CuONPs and control treatments that resulted in a distinct increase in total chlorophyll in potato plants after 20 and 40 days of planting. Consistent with these results, Jhansi et al. (2017) indicated that soaking of peanut seeds in a $500 \mu \mathrm{g} / \mathrm{mL}$ MgONP for $12 \mathrm{~h}$ enhanced the chlorophyll content in plant leaves. Moreover, after 30 days of treatment, Cai et al. (2018b) demonstrated that MgONPs increased chlorophyll $a$ and $b$ contents in tobacco plants. Additionally, Raliya et al. (2014) demonstrated that MgONPs improved shoot-root growth with values reached 18.2 to $49.2 \%$ and chlorophyll photosynthetic pigment $(76.1 \%)$ in clusterbean (Cyamopsis tetragonoloba). Treatment with CuONPs at all concentrations exhibited also positive impact on the chlorophyll content when compared to untreated control. However, Yang et al. (2020) demonstrated the contrary, in which chlorophyll $a$ and chlorophyll $b$ and carotenoid content in rice leaves were decreased after 7 days of exposure to CuONP. Also, Pontes et al. (2020) indicated that CuONPs negatively affected the chlorophyll $a$ content in duckweed leaves. Moreover, the results of Santos et al. (2021) confirmed the negative impact of CuONPs on the maximum emission of chlorophyll a, which was concentrationdependent and inhibited root growth of Sesbania virgata plants.

According to Biswas et al. (2012) phenols are involved in disease resistance in many ways such as lignification of cell walls, hypersensitive cell death, etc. In this concern, highest phenol content was recorded with treatment of MgONPs at $200 \mathrm{mg} / \mathrm{L}$, which showed decrease trend with decreasing concentration. However, Ramadan et al. (2020) documented that the highest phenol content was obtained by lower concentration $20 \mathrm{ppm}$ of MgONPs. AbdelWahab et al. (2019) demonstrated that lower concentrations 50, 100 and $150 \mathrm{mg} / \mathrm{L}$ of CuONPs increased phenolic compounds in callus cells of Solanum nigrum, while the higher concentration of $200 \mathrm{mg} / \mathrm{L}$ significantly decreased it. A similar kind of findings was observed by Sarkar et al. (2020) who indicated that the optimum concentration of CuONPs was found, $0.025 \mathrm{mg} / \mathrm{mL}^{-1}$, which showed higher production of phenol and flavonoid. Contrarily, our results indicated that the concentration of $200 \mathrm{mg} / \mathrm{L}$ of $\mathrm{CuONPs}$ increased the phenol content in potato leaves when compared to lower concentrations and control.

Energy Dispersive X-ray (EDX) could be necessary for a positive detection of the nanomaterials in tissues and cells (De Jong et $a l ., 2010)$. This study indicated the translocation of NPs from treated mother tubers to aerial parts after plantation and accumulated in daughter tubers. Our finding is supported by previous work of Rico et al. (2011) and Tripathi et al. (2017) who reported that NPs could transfer through roots to plant shoot and seeds. The accumulation of NPs in edible plant tissues is a critical issue that could impact human health via the food chain. In this regard, the study of Barakat et al. (2019) revealed that CuONPs caused DNA damage and histopathological alteration in the brain and the lungs of adult male albino rats. Previous studies have reported also that $\mathrm{TiO}_{2} \mathrm{NPs}$ and FeNPs caused lung damage and cytotoxic and genotoxic effects in rats (Gonzalez et al., 2008; Fraser et al., 2011 and Mohamed and Hussien, 2016). Furthermore, $\mathrm{TiO}_{2} \mathrm{NPs}$ and fullerene have been shown to cause brain damage in fish and dogs (Shaw and 
Handy, 2011). Therefore, the application of NPs requires further interdisciplinary research work by involving scientists, medical researchers, toxicologists and environmental engineers.

\section{REFERENCES:}

Abd El-Aziz, A.R.M.; Mahmoud, M.A.; AlOthman, M.R..; Abedel-Sattar, M.A.; ElSherif, E.M. and El-Marzouky, H. 2013. Differential interaction between isolates of Rhizoctonia solani AG-3 and potatoes cultivars. Afr. J. Microbiol. Res., 7(12):10451054.

Abdel-Wahab, D.A.; Othman, N.A.R.M. and Hamada, A.M. 2019. Effects of copper oxide nanoparticles to Solanum nigrum and its potential for phytoremediation. Plant Cell Tissue Organ Cult., 137(3): 525-539.

Ahmed, T.; Noman, M.; Luo, J.; Muhammad, S.; Shahid, M.; Ali, Md.A.; Zhanga, M. and Li, B. 2021. Bioengineered chitosanmagnesium nanocomposite: A novel agricultural antimicrobial agent against Acidovorax oryzae and Rhizoctonia solani for sustainable rice production. Int. J. Biol. Macromol., 168: 834-845.

Allam, A.I. and Hollis, J.P. 1972. Sulfide inhibition of oxidases in rice roots. Phytopathology, 62:634-636.

Arnon, D.I. 1949. Copper enzymes in isolated chloroplasts. Polyhenoloxidases in Beta vulgaris. Plant Physiol., 24: 1-15.

Bakali, A.M.E. and Martín, M.P. 2006. Black scurf of potato. Mycologist., 20: 130-132.

Ball, P. 2002. Natural strategies for the molecular engineer. Nanotechnology, 13(5): 15-28.

Banyal, D.K. 2002. Management of tuber-borne diseases of potato. Plant Dis. Res., 17(2): 323-324.

Barakat, W.; Wasef, M.; Abass, M. and Elnegris, H. 2019. A Study of Short Term Chronic Pulmonary Toxicity, Neurotoxicity and Genotoxicity of Copper Oxide Nanoparticles and The Potential Protective Role of Vitamin E on Adult Male Albino Rats. Zagazig J. Forensic. Med. Toxicology, 17(2):1-18.

Biswas, S.K.; Pandey, N.K. and Rajik, M. 2012. Inductions of defense response in tomato against Fusarium wilt through inorganic chemicals as inducers. J. Plant Pathol. Microbiol., 3:1-7.

Cai, L.; Chen, J.N.; Liu, Z.W.; Wang, H.C.; Yang, H.K. and Ding, W. 2018a. Magnesium oxide nanoparticles: effective agricultural antibacterial agent against Ralstonia solanacearum. Front. Microbiol., 9: 790.

Cai, L.; Liu, M.; Liu, Z.; Yang, H.; Sun, X.; Chen, J.; Xiang, S. and Ding, W. 2018b. MgONPs Can boost plant growth: evidence from increased seedling growth, morphophysiological activities, and $\mathrm{Mg}$ uptake in Tobacco (Nicotiana tabacum L.). Molecules, 23: 3375 .

Chen, J.; Wu, L.; Lu, M.; Lu, S.; Li, Z. and Ding, W. 2020. Comparative study on the fungicidal activity of metallic $\mathrm{MgO}$ nanoparticles and macroscale $\mathrm{MgO}$ against soilborne fungal phytopathogens. Front. Microbiol., 11: 365.

Da Costa, M.V.J. and Sharma, P.K. 2016. Effect of copper oxide nanoparticles on growth, morphology, photosynthesis and antioxidant response in Oryza sativa. Photosynthetica, 54: 110-119.

De Jong, W.H.; Burger, M.C.; Verheijen, M.A. and Geertsma, R.E. 2010. Detection of the presence of gold nanoparticles in organs by transmission electron microscopy. Materials, 3: 4681-4694.

El-Argawy, E.; Rahhal, M.M.H.; El-Korany, A.; Elshabrawy, E.M. and Eltahan, R.M. 2017. Efficacy of some nanoparticles to control damping-off and root rot of sugar beet in ElBehiera Governorate. Asian J. Plant Pathol., 11: 35-47.

Elmer, W.H. and White, J.C. 2016. The use of metallic oxide nanoparticles to enhance growth of tomatoes and eggplants in disease infested soil or soilless medium. Environ. Sci. Nano., 3: 1072-1079.

El-Shewy, E.S.A.; Mohemed, F.G.; Abd-latif, F.M.; Hafez, E.M. and Mansour, S.A. 2019. The efficacy of copper oxide, tri-calcium phosphate and silicon dioxide nanoparticles in controlling black scurf disease of potato. Ann. Agric. Sci. Moshtohor, 57: 129-138.

Fang, X.; Finnegan, P.M. and Barbetti, M.J. 2013. Wide variation in virulence and genetic diversity of binucleate Rhizoctonia isolates associated with root rot of strawberry in Western Australia. PLoS One, 8(2): 1-14.

Fraser, T.W.K.; Reinardy, H.C.; Shaw, B.J.; Henry, T.B. and Handy, R.D. 2011. Dietary toxicity of single-walled carbon nanotubes and fullerenes (C60) in rainbow trout (Oncorhynchus mykiss). Nanotoxicology, 5: 98-108.

Giannousi, K.; Avramidis, I. and DendrinouSamara, C. 2013. Synthesis, characterization and evaluation of copper-based nanoparticles 
as agrochemicals against Phytophthora infestans. RSC Adv., 3: 21743-21752.

Gichuhi, P.N.; Kpomblekou-A, K. and BovellBenjamin, A.C. 2014. Nutritional and physical properties of organic Beauregard sweet potato [Ipomoea batatas (L.)] as influenced by broiler litter application rate. Food Sci. Nutr., 2(4):332-340.

Gonzalez, L.; Lison, D. and Kirsch-Volders, M. 2008. Genotoxicity of engineered nanomaterials: a critical review. Nanotoxicology, 2: 252-273.

Grover, R.K. and Moore, J.D. 1962. Toximetric studies of fungicides against the brown rot organisms, Sclerotinia fruticola and S. laxa. Phytopathology, 52: 876-880.

Hao, Y.; Fang, P.H.; Ma, C.X.; White, J.C.; Xiang, Z.Q. and Wang, H.T. 2019. Engineered nanomaterials inhibit Podosphaera pannosa infection on rose leaves by regulating phytohormones. Environ. Res., 170: 1-6.

Hassan, M.S.S.; Monir, G.A. and Radwan, M.A. 2021. Efficacy of certain essential oils, copper oxide, copper oxide nanoparticle, Imazalil and Bacillus subtilis to control fruit rot of avocado. Egypt. J. Phytopathol., (49)1: 166-181.

Huber, D.M. and Jones, J.B. 2013. The role of magnesium in plant disease. Plant Soil, 368: 73-85.

Jeger, M.J.; Hide, G.A.; van den Boogert, P.H.J.F.; Termorshuizen, A.J. and van Baarlen, P. 1996. Soilborne fungal pathogens of potato. Potato Res., 39: 437-469.

Jhansi, K.; Jayarambabu, N.; Reddy, K.P.; Reddy, N.M.; Suvarna, R.P.; Rao, K.V.; Kumar, V.R. and Rajendar, V. 2017. Biosynthesis of $\mathrm{MgO}$ nanoparticles using mushroom extract: Effect on peanut (Arachis hypogaea L.) seed germination. Biotech., 7: 263.

Kanhed, P.; Birla, S.; Gaikwad, S.; Gade, A.; Seabra, A.B.; Rubilar, O.; Duran, N. and Rai, M. 2014. In vitro antifungal efficacy of copper nanoparticles against selected crop pathogenic fungi. Mater. Lett., 115: 13-17.

Kankam, F.; Larbi-Koranteng, S. and Adomako, J. 2021. Rhizoctonia disease of potato: Epidemiology, toxin types and management. Egypt. J. Phytopathol., 49(1): 197-209.

Karamanos, R.E.; Pomarenski, Q.; Goh, T.B. and Flore, N.A. 2004. The effect of foliar copper application on grain yield and quality of wheat. Can. J. Plant Sci., 84: 47-56.
Khandaker, M.D.M.; Khair, A.; Bhuiyan, M.D.K.A. and Begum, H.H. 2012. Control measures of stem canker and black scurf disease of potato in naturally infested field. Jagannath University Journal of Science, 1 (11): 79-85.

Liao, Y.Y.; Strayer-Scherer, A.; White, J.C.; De La Torre-Roche, R.; Ritchie, L.; Colee, J.; Vallad, G.E.; Freeman, J.; Jones, J.B. and Paret, M.L. 2019. Particle-size dependent bactericidal activity of magnesium oxide against Xanthomonas perforans and bacterial spot of tomato. Sci. Rep., 9(1): 18530.

Matta, A.I. and Dimond, A.F. 1963. Symptoms of Fusarium wilt in relation to quantity of fungus and enzyme activity in tomato stems. Phytopathology, 53: 574-578.

Mohamed, H.R.H. and Hussien, N.A. 2016. Genotoxicity studies of titanium dioxide nanoparticles $\left(\mathrm{TiO}_{2} \mathrm{NPs}\right)$ in the brain of mice. Scientifica, 2016: 6710840.

Nair, P.M.G. and Chung, I.M. 2014. Impact of copper oxide nanoparticles exposure on Arabidopsis thaliana growth, root system development, root lignification, and molecular level changes. Environ. Sci. Pol. Res., 21: 12709-12722.

Ngo, B.Q.; Dao, T.T.; Nguyen, C.H.; Tran, X.T.; Nguyen, T.V.; Khuu, T.D. and Huynh, T.H. 2014. Effects of nanocrystalline powders $(\mathrm{Fe}, \mathrm{Co}$ and $\mathrm{Cu})$ on the germination, growth, crop yield and product quality of soybean (Vietnamese species DT-51). Adv. Nat. Sci. Nanosci. Nanotechnol., 5: 015016.

Ouda, S.M. 2014. Antifungal activity of silver and copper nanoparticles on two plant pathogens, Alternaria alternata and Botrytis cinerea. Res. J. Microbiol., 9: 34-42.

Oussou-Azo, A.F.; Nakama, T.; Nakamura, M.; Futagami, T. and Vestergaard, M.C.M. 2020. Antifungal potential of nanostructured crystalline copper and its oxide forms. Nanomaterials, 10: 1-13.

Parizi, M.A.; Moradpour, Y.; Roostaei, A.; Khani, M.; Negahdari, M. and Rahimi, G. 2014. Evaluation of the antifungal effect of magnesium oxide nanoparticles on Fusarium oxysporum f. sp. lycopersici, pathogenic agent of tomato. Eur. J. Exp. Biol., 4: 151156.

Pontes, M.S.; Graciano, D.E.; Antunes, D.R.; Santos, J.S.; Arruda, G.J.; Botero, E.R.; Grillo, R.; Lima, S.M.; Andrade, L.H.C.; Caires, A.R.L. and Santiago, E.F. 2020. In vitro and in vivo impact assessment of ecodesigned $\mathrm{CuO}$ nanoparticles on non-target 
aquatic photoautotrophic organisms. J. Hazard. Mater., 396: 122484.

Raffi, M.; Mehrwan, S.; Bhatti, T.M.; Akhter, J.I.; Yawar, A.W. and Masood ul Hasan, M. 2010. Investigations into the antibacterial behavior of copper nanoparticles against Escherichia coli. Ann. Microbiol., 60(1): 7580.

Rai, M.; Ingle, A.P.; Paralikar, P.; Anasane, N.; Gade, R. and Ingle, P. 2018. Effective management of soft rot of ginger caused by Pythium spp. $\quad$ and Fusarium spp.: emerging role of nanotechnology. Appl. Microbiol. Biotechnol., 102: 6827-6839.

Raliya, R.; Tarafdar, J.C.; Singh, S.K.; Gautam, R.; Choudhary, K.; Maurino, V.G. and Saharan, V. 2014. MgO nanoparticles biosynthesis and its effect on chlorophyll contents in the leaves of clusterbean (Cyamopsis tetragonoloba L.). Adv. Sci. Eng. Med., 6: 538-545.

Ramadan, A.A; El-Bassiouny, H.M.S.; Bakry, B.A.; Abdallah, M.M.S. and El-Enany, M.A.M. 2020. Growth, yield and biochemical changes of soybean plant in response to iron and magnesium oxide nanoparticles. Pak. J. Biol. Sci., 23: 406-417.

Rauf, C.A.; Ashraf, M. and Ahmad, I. 2007. Occurrence and distribution of black scurf of potato in Pakistan. Pak. J. Bot., 39(4):13411352.

Regier, N.; Cosio, C.; von Moos, N. and Slaveykova, V.I. 2015. Effects of copperoxide nanoparticles, dissolved copper and ultraviolet radiation on copper bioaccumulation, photosynthesis and oxidative stress in the aquatic macrophyte Elodea nuttallii. Chemosphere, 128: 56-61.

Rico, C.M.; Majumdar, S.; $\quad$ Duarte-Gardea, M.; Peralta-Videa, J.R. and Gardea-Torresdey, J.L. 2011.Interaction of nanoparticles with edible plants and their possible implications in the food chain. J. Agric. Food Chem., 59: 3485-3498.

Rodriguez-Gonzalez, V.; Dominguez-Espindola, R.B.; Casas-Flores, S.; Patron-Soberano, O.A.; Camposeco-Solis, R. and Lee, S.W. 2016. Antifungal nanocomposites inspired by titanate nanotubes for complete inactivation of Botrytis cinerea isolated from tomato infection. ACS Appl. Mater. Interfaces, 8: 31625-31637.

Saied, E.; Eid, A.M.; Hassan, S.E.D.; Salem, S.S.; Radwan, A.A.; Halawa, M.; Saleh, F.M.; Saad, H.A.; Saied, E.M. and Fouda, A. 2021. The catalytic activity of biosynthesized magnesium oxide nanoparticles (MgO-NPs) for Inhibiting the growth of pathogenic microbes, tanning effluent treatment, and chromium ion removal. Catalysts, 11: 821 .

Santos, E.S.D.; Graciano, D.E.; Falco, W.F.; Caires, A.R.L. and Arruda, E.J. 2021. Effects of copper oxide nanoparticles on germination of Sesbania virgata (FABACEAE) plants. An. Acad. Bras. Cienc., 93(3): e20190739.

Sarkar, J.; Chakraborty, N.; Chatterjee, A.; Bhattacharjee, A.; Dasgupta, D. and Acharya, K. 2020. Green synthesized copper oxide nanoparticles ameliorate defense and antioxidant enzymes in Lens culinaris. Nanomaterials, 10(2): 312.

Scimeca, M.; Bischetti, S.; Lamsira, H.K.; Bonfiglio, R. and Bonanno, E. 2018. Energy Dispersive X-ray (EDX) microanalysis: A powerful tool in biomedical research and diagnosis. Eur. J. Histochem., 62(1): 1-10.

Sharon, M.; Kuninaga, S.; Hyakumachi, M.; Naito, S. and Sneh, B. 2008. Classification of Rhizoctonia spp. using RDNA-ITS sequence analysis supports the genetic basis of the classical anastomosis grouping. Mycoscience, 49: 93-114.

Shaw, B.J. and Handy, R.D. 2011.Physiological effects of nanoparticles on fish: a comparison of nanometals versus metal ions. Environ. Int., 37(6): 1083-1097.

Singh, A.; Singh, N.B.; Hussain, I. and Singh, H. 2017. Effect of biologically synthesized copper oxide nanoparticles on metabolism and antioxidant activity to the crop plants Solanum lycopersicum and Brassica oleracea var. botrytis. J. Biotechnol., 262: 11-27.

Snedecor, G.W. and Cochran, W.G. 1980. Statistical Methods. $7^{\text {th }}$ Ed, Iowa State University Press, Ames. 507 pp.

Snell, F.D. and Snell, C.I. 1953. Colorimetric Methods. Vol. III. D. Van Nostrand Co. Inc., Torento, N. Y., London, 606 pp.

Su, S.; Zhou, Y.; Qin, J.G.; Yao, W. and Ma, Z. 2010. Optimization of the method for chlorophyll extraction in aquatic plants. J. Freshw. Ecol., 25:4:531-538.

Sun, Q.; Li, J.M. and Le, T. 2018. Zinc oxide nanoparticle as a novel class of antifungal agents: current advances and future perspectives. J. Agric. Food Chem., 6: 11209-11220.

Tripathi, D.K.; Shweta, Singh, S.; Singh, S.; Pandey, R.; Singh, V.P.; Sharma, N.C.; Prasad, M.; Dubey, N.K. and Chauhan, D.K. 2017. An overview on manufactured nanoparticles in plants: uptake, translocation, accumulation and phytotoxicity. Plant Physiol. Biochem., 110: 2-12. 
Wani, A. and Shah, M. 2012. A Unique and profound effect of $\mathrm{MgO}$ and $\mathrm{ZnO}$ nanoparticles on some plant pathogenic fungi. J. Appl. Pharm. Sci., 2: 40-44.

White, T.J.; Bruns, T.; Lee, S. and Taylor, J.W. 1990. Amplification and direct sequencing of fungal ribosomal RNA genes for phylogenetics. In: Innis M.A., Gelfand, D.H., Sninsky, J.J., White, T.J. (eds) PCR protocols: A Guide to Methods and Applications. pp 315-322. Academic Press, Inc., New York, USA.

Xi, J.; Zhang, Z.; Zhu, Q. and Zhong, G. 2018. Evolution from natural b-Carboline alkaloids to obtain 1,2,4,9-tetrahydro-3-thia-9-azafluorene derivatives as potent fungicidal agents against Rhizoctonia solani. Int. J. Mol. Sci., 19: 4044.

Xue, Y.; Yue, S.; Zhang, W.; Liu, D.; Cui, Z.; Chen, X.; Ye, Y. and Zou, C. 2014. Zinc, iron, manganese and copper uptake requirement in response to nitrogen supply and the increased grain yield of summer maize. PLoS One, 9: e93895.

Yang, Z.; Xiao, Y.; Jiao, T.; Zhang, Y.; Chen, J. and Gao, Y. 2020. Effects of copper oxide nanoparticles on the growth of Rice (Oryza Sativa L.) seedlings and the relevant physiological responses. Int. J. Environ. Res., 17(4): 1260.

Zachow, C.; Grosch, R. and Berg, G. 2011. Impact of biotic and a-biotic prameters on structure and function of microbial communities living on sclerotia of the soilborne pathogenic fungus Rhizoctonia solani. Appl. Soil Ecol., 48(2): 193-200.

Zelalem, A.; Tekalign, T. and Nigussie, D. 2009. Response of potato (Solanum tuberosum L.) to different rates of nitrogen and phosphorus fertilization on vertisols at Debre Berhan, in the central highlands of Ethiopia. Afr. J. Plant Sci., 3:016-024. 